DOI: $10.24818 / \mathrm{SYN} / 2021 / 17 / 2.10$

\title{
ACADEMIC LITERACY DEVELOPMENT. PERSPECTIVES ON MULTILINGUAL SCHOLARS' APPROACHES TO WRITING
}

\author{
Laura-Mihaela Mureșan \& Concepción Orna-Montesinos (Editors) \\ Palgrave MacMillan 2021; 356 pg.
}

\begin{abstract}
Anca-Teodora ŞERBAN-OPRESCU ${ }^{1}$
We all know that considerable amounts of literature have been written on 'how to' write and deliver academic papers, end of undergraduate studies theses, end of Master dissertations, or $\mathrm{PhD}$ similar works. Not to mention various project proposals for undergraduate and graduate studies.

Nonetheless, the volume under scrutiny proposes a different approach to the rich field of writing in and for academic settings and, through the various aspects proposed that analyze the phenomenon of academic writing in kaleidoscopic manner, results in a meticulous and fashionable meta-text on the highly subjective and sensitive issue of the genre.
\end{abstract}

Which is the current picture of academic literacy development - from theory stance? What does it mean to start as a novice, or become 'literate' in the academic language and structure? Adapting and obliging disciplinary norms and discourse conventions established within discourse community are pre-requisites for being accepted, or seen as 'acculturated' in these academic settings. But which are the steps that novices in this field need to take and, once there, what further caveats do they need to observe?

These are only some of the questions that the volume addresses, giving lengthy and detailed accounts divided into 4 Parts gathering a total of 17 Chapters that view and review matters brought into discussion in a multi-faceted and triangulated manner.

Along with aspects regarding theoretical enquiry into the vast field of academic writing, there is also significant effort put into the critical aspect of educating and training for those looking to enter and perform in academia, or training in Languages for Academic Purposes (LAP), as the editors astutely direct attention. To quasi-quote some of the questions asked in the Foreword to the volume: How can LAP researchers and practitioners discover the strengths and obstacles that

1 Anca-Teodora Șerban-Oprescu, Bucharest University of Economic Studies, teodora.oprescu@rei.ase.ro 
academic writers find in their endeavor to develop in this area? How can one identify and assess the extent to which past writing experiences, writing feedback and the use of writing strategies trigger literacy development? How can novice writers' perceptions of their own development as academic writers be collected, analysed and interpreted to inform and guide university policy with regard to writing programmes and LAP materials? What are the best ways for writing instructors to deposit and use good practice in order to assist novice writers in this particular learning experience?

The ability of the Editors - two well-established researchers and strong voices in the field - to build the discussion from both perspectives: that of the body of knowledge in the field and empirical data from working with such writers-intraining informs a very complex and tailored to needs point of view. One that comes from both theory and practice, plus experience. And this is something that few materials on the subject manage to illustrate.

Of course, the above questions are only starting grounds and new perspectives become relevant as each Chapter unfolds. The volume attempts and succeeds to examine the intricate process of developing academic writing skills and describes the stages that beginner (or novice) writers experience as they go through acquiring and mastering skills in the use of language for academic and research communication purposes.

The 4 Parts of the volume build the argument in logical, progressive manner. Part 1: Language Policies and Academic Literacy, lays the ground for the theoretical aspects of the field to be taken into consideration. Part 2: Developing and Linking Literacies: Academic Professional Literacy and Genre-Related Literacy puts theory into practice and looks at case-study body of evidence to give flesh to the theoretical structure discussed in the first Part. Part 3: Agency, Identity and Selfrepresentation in Literacy Development and Part 4: Individual Trajectories in Academic Literacy Development, consider matters from a more personal, individual perspective, subjective experience of the writers and writers-in-training in this field.

As such, the endeavor takes the reader from a general bird's eye view of the field, to the particular - worm's eye view, offering a comprehensive, timely and realistic study of academic literacy development in present context. Additionally, the general validity of the analyses, conclusions and discussions comprised in the volume relies on the authors comprised in the book; just a quick glance at these authors, coming from universities and academic environments based in different parts of the United States, but also Macedonia, Canada, Colombia, Finland, Australia, Romania, Spain, embodying an authentic academic voyage around the world, gathering all these perspectives on the topic, is undeniable proof of the reliability of the assertions made in study of the development of academic literacy.

SYNERGY volume 17, no. $2 / 2021$ 